\title{
Medical ethics: who decides what?
}

\author{
Michael Kottow Charlottenklinic for Ophthalmology, Stuttgart, West Germany
}

\section{Author's abstract}

The $\mathcal{F M E}$ symposium on teaching medical ethics takes up the issue of competence and responsibility in matters concerning bioethics (1). Foreseeably, the medical participants argue that physicians are prepared, or can be easily prepared, to handle all relevant aspects of medical ethics. The contrary position is sustained by the philosophically trained participants, who believe that physicians do not, in fact cannot, sufficiently manage medico-ethical problems. This paper sees a role for both parties. Medical ethicists should properly be involved in medical education and in analytical and systematic study of medical ethics. They should not generally be involved in clinical medico-moral decision-making, which is properly the realm of patient and (ethically competent) doctor.

\section{Physicians as ethicists}

The main point of Professor Swales's argument defends a clinical setting where the scope of medical decisions is maximally enlarged (2). While the existence of value judgments is not denied, they are simply incorporated as 'part and parcel' of clinical work. An ethicist is therefore misplaced at the level of clinical judgment. So far, this is an arguably conservative stance, which construes its position on the implicit premise that physicians have a classical education, are widely read, and have become finely-honed intellectuals capable of mastering their discipline and of predicting the moral consequences of their decisions. Beyond that, Professor Swales's analysis shows three perilous pitfalls.

The first one is to consider clinical activity sufficiently characterised by its scientific component. There is wide though not unanimous agreement that clinical judgment, notably diagnosis, is based on, or at least strongly influenced by, scientific elements (3). But not even this more disciplined part of clinical judgment is so scientific as to be constituted of hypotheses amenable to corroboration or rejection through direct observation and experimentation. Much of medical practice is actually never subjected to epistemological

\section{Key words}

Medical ethics; medical ethicists; medical education. control or correction (4). Diagnostic labels are not so much exact descriptions of an infirmity, but rather working hypotheses to direct therapy (5). After treatment is instituted the patient, say, improves: was this due to the specific element of therapy, to the non-specific components of the therapeutic situation of care, rest, less smoking and lighter eating, or was improvement perhaps coincidental but unrelated to the institution of therapy?

In addition to being infested with untestable assertions, clinical activity is thoroughly permeated by valuative and normative aspects which are amenable to ethical analysis. To declare someone ill and label her with specific disease-tags has normative consequences that impinge on the rights and duties of the individual (6). It does not suffice to say, as Professor Swales does, that clinical judgment has an element of uncertainty to it, rather it must be accepted that diagnosis and therapy are, to offer a very simplistic formula, science - of a peculiar nature - plus ethics.

Secondly, inasmuch as he accepts ethical components in medical decisions, Professor Swales considers physicians to be sufficiently capable of handling these situations, equipped with an average knowledge of utilitarian ethics. Religiously orientated ethicists, he claims, have too parochial a view to bring forth generally acceptable contributions, whereas 'experts' in ethics are medically too uninformed to be of help to any but the most inexperienced members of medical teams. True, medical ethics has become a selfsustaining, occasionally redundant discipline that is often divorced from medical practice and its concerns. But this line of argumentation dismisses the fact that physicians are, by education, idiosyncrasy and interests, no better equipped to handle ethical matters than other laypeople (7). Otherwise, there would be little need for oaths, codices, symposia, books, journals or courses on medical ethics.

Medicine is a solution-orientated, pragmatic activity, but its ethical dilemmas are not exhausted by utilitarianism. Experimental research with uninformed human beings has a tremendous potential to increase medical knowledge and benefit present and future generations. And yet, no simplistic utilitarian consideration can efface the fact that this kind of enterprise is unacceptable on deontological grounds related to 
autonomy and respect for the individual (8). Physicians have often disregarded rights of patients and nonmedical ethicists have contributed to a rekindled interest in these matters, so that, all in all, past performance tips the balance against physicians being autonomous and good ethicists.

Thirdly, Professor Swales contends that scientific work functions independently of philosophical concerns. By analogy, medicine could do without ethical philosophy. However, there is an important difference between science and medicine. The main function of science is explanatory, an activity that has no ethical dimension per se, unless scientists get concerned with the reasons why certain problems are being attacked and others neglected, or become suspicious about applications of their explanations. Otherwise, there is no primary reason why scientists should be orientating their activities in accordance with metascientific philosophical inquiry. Medicine, on the contrary, is an activity tightly meshed with ethical considerations and is therefore bound to benefit from increased awareness of moral issues. Philosophical concern with bioethics is fundamentally analytic, but it also has a strong normative component that is bound to influence medical practice.

Professor Swales, in sum, considers medicine ethically self-sufficient and rejects the grafting of bioethicists into the clinical setting. In this dislike he is not alone, for in the same symposium it is argued that ethics committees, codes of ethics and bioethicists' advice are untimely and inefficient normative instruments compared to the law, and that only adequate legislation could eventually offer ethical guidelines on controversial medico-ethical issues (9). In other words, the bioethicist's place is not in the wards, but in court and in parliament. This analysis disregards the fact that most collisions between ethics and the law address excessive rather than too sparse legislation. Abortion is explicitly prohibited or limited, euthanasia is not allowed or equated with murder, involuntary commitment is expressly authorised, the introduction of pharmacological agents is tightly regulated. All these are examples of current protectionist legislation that reduces ethical leeway and narrows liberty down to a minimum. It is true that additional liberal legislation has softened previous absolutism, but what ethicists should aim at is, fundamentally, de-legislation. Only thus will ethical decisions be extricated from the rigidity of the law and regain the true possibilities of alternative actions chosen in freedom.

The symposium participants are right in rejecting Professor Swales's bon mot that medical ethics is too important a subject to merit curricular autonomy. If it is so essential, then it becomes irrelevant in which form ethics is taught, provided the curriculum does not neglect the subject. Equally secondary, because obvious, is the point made by Dr Smith that knowledge of medico-ethical issues cannot be divorced from familiarity with general ethics.

\section{Bioethicists in clinical settings}

Probably the most fruitful controversy of the symposium on the importance of medical ethics is the one addressing the intersection between clinical decisions and ethical decisions. Professor Swales sees no distinction between the two kinds of judgment and consequently denies the necessity for a philosophical expert to cover ethics in medicine. His detractors claim that occasionally medical issues masquerade as ethical ones and vice versa, but that a fundamental separation between the two types of judgment is possible and desirable (10). Unfortunately, they support their argument with faulty examples. Whether a woman with breast cancer should have lumpectomy or radical mastectomy is definitely not an ethical issue, it is a matter of clinical judgment as to which method more effectively treats the disease. If she prefers a less safe but cosmetically acceptable lumpectomy because otherwise her marriage might suffer, she may be legitimately disregarding sound medical advice, but nothing in this example addresses a conflict of medical ethics.

But there are, undoubtedly, many instances of medico-ethical judgments that require a broad view of the patient's circumstances and interests. Arras and Murray flatly deny that physicians are capable of overall assessment of patients' circumstances in ethically explosive situations, and they base their misgivings on the assumption that physicians are encased in behaviour patterns that are non-conducive to this sort of enlightened attitude. Impersonal patient/ physician relationships, they claim, also mitigate against the physician's acceptance of the patient as a human being rather than merely a clinical case.

If this part of Arras and Murray's essay is correct, then medicine is in deep trouble. For it would appear that physicians cannot but relate deficiently with their patients, unless guided and taught by enlightened bioethicists. As previously noted, doctors are in fact not particularly well equipped to handle moral problems, but to make a matter of principle out of this average insufficiency seems unwarranted and prejudiced.

Whether physicians are so dull and callous, bioethicists so judicious, and ethical judgment so smoothly transferable from philosophers to physicians, are all matters of opinion. But it repeatedly occurs that bioethicists illustrate this point with unimaginative examples. Thus, the misguided surgeon portrayed by Arras and Murray, who doesn't face his technical errors, deserves a malpractice suit rather than ethical counselling. At this level of gross medical misjudgment, one can hardly find support for the role of an ethicist. Every reasonable clinician will accept that professional review, legal control and economic sanctions should regulate unethical medical conduct or coarse technical errors. Nor, to comment on another example of this symposium, does an ethicist seem necessary to discourse on the reasons for scarcity of life-saving medical resources. He may, though, con- 
tribute importantly to the related problem of triage or similar decision-making issues.

\section{Medical ethics as a two-tiered system}

The cleavage between medical and ethical issues, or rather between the judgments that are part and parcel of the physician's realm and those that can be illuminated by bioethicists, remains unclear (11). When is a decision clinical, when is it ethical? Does it help to suggest that the two realms are inextricable, that they actually merge into one conglomerate of multifaceted aspects? The symposium on medical ethics shows that agreement on these matters is far from being in sight and that a watershed between the two areas needs to be worked out.

Medicine's concern is the individual human organism. Not the body, which is but a mechanical, Cartesian conflation of material parts devoid of reflectivity, but the organism as a structured interconnection of organs that show subjectivity and purpose (12). In Aristotelian language, living beings are defined as 'soma organika', that is, as instrumental bodies. Since the organism has sufficient reflectivity to pursue its own purposes, it can also participate, conjointly with the medical team, in all decisions concerning its medical care. Precisely because medicine is concerned with a purpose-orientated organism, it can hardly escape ethical issues related to the organism and its purposes. An organism that sees its purpose of survival thwarted by lethal disease may prefer death to frustration. An organism with coronary disease may decide, in agreement with its physicians, that risky bypass surgery is preferable to a handicapped life. On the basis of this kind of issue it was stated above that clinical judgment is science plus ethics. But because the alternatives concern performing or refraining from carrying out a medical act, it appears plausible to state, as in the case of the woman with breast cancer, that these decisions are medical ones involving patient and physician, but not necessarily an ethical counsellor.

Humans are, of course, insufficiently characterised as organisms. Their inter-individual relationships and metaphysical concerns make them persons. Persons are affected by their organic and psychic derangements, but the resultant effect cannot be fully thrown in the lap of medicine. The organic realm and its malfunctions are important parts of the person, but they must nevertheless share valuative space with other personal concerns. Here one enters the ethical realm and clears the way for metamedical thinking in bioethics. Medicine is therefore attentive to the individual qua organism, whereas bioethics is involved with the organism qua person. That organic concerns must remain in the hands of medicine is undisputed. Whether bioethical stances should be exacted from physicians, indirectly brought to their attention by philosophical discourse, or definitely delegated to bioethical specialists, remains a question of insuffi- ciently discussed strategy.

This suggests a two-tiered decisional system, where the first level is the clinical one. Here physicians and patients carry the brunt of decisions concerning clinical judgment. Clinical and ethical aspects can hardly be separated and therefore cannot be delegated at this level. How should one, for example, explore an organism for cancer without suggesting the diagnosis one is working with? At the clinical level, physicians must possess, or achieve, ethical competence and autonomy, to which purpose bioethical counselling or, better still, curricular involvement with ethics during medical studies, appears to be essential. Still more vital is the disengagement of medico-ethical decisions from questions of status, economic advantage or commitments to professional group-interests.

An ethically well-informed medical team should be fully in command of the clinical level of decisionmaking. This includes not only medical care in its technical aspects, but ethical issues like truth-telling, information, confidentiality, counselling, decisions on abortion, euthanasia and suspension of treatment. Problems and solutions in this ambit fit into the dimensions of casuistry and can be known inferentially (13). The less a bioethicist needs to get involved in these issues, the more mature and competent can the performance of the medical team be rated.

The second level of the two-tiered system is transclinical and pursues the more analytical and systematic aspects of medical ethics. Clinical decisions are here not relevant, but case analysis may serve as paradigmatic material to relate general ethical considerations to specific medical problems. Bioethicists play a major role at this level and their function is to advise legislative powers (abortion laws, macroallocation of resources, regulation of medical associations), and the judiciary (law suits concerning medical practices, psychiatric commitment rulings, proxy decisions), and to evaluate the implementation of medical decisions (microallocations, extraordinary therapeutics, experimental medicine). Serving on committees, in advisory departments, through academic activities and teaching posts, bioethicists must convince, without aspiring to a legal status that would enforce the results of their deliberations. This would be contrary to ethical thought and academic freedom. Bioethical activity must gain force on the basis of its coherence and relevance, becoming, one hopes, increasingly influential to the point where no medical decision will be taken that is contrary to sound bioethical thinking.

\section{References}

(1) Symposium: Is medical ethics 'too important for a separate place in the curriculum'? Fournal of medical ethics 1982; 8: 117-127.

(2) Swales J D. Medical ethics: some reservations. Fournal of medical ethics 1982; 8: 117-119.

(3) Forstrom L. The scientific autonomy of clinical medicine. Fournal of medicine and philosophy 1977; 8-19. 
(4) Scriven M. Clinical judgement. In: Engelhardt Jr H T, Spicker S F, Towers B, eds. Clinical judgement: a critical appraisal. Dordrecht: D Reidel, 1979: 3-16. Spicker S F, Towers B, eds. Clinical judgment: a critical appraisal. Dordrecht: D Reidel, 1979: 3-16.

(5) Whitbeck C. What is diagnosis? Some critical reflections. Metamedicine 1981; 2: 319-329.

(6) Engelhardt Jr H T. Clinical judgement. Metamedicine $1981 ; 2: 301-317$.

(7) Gorovitz S. The physician as moral arbiter. In: Bonderson W B, Engelhardt Jr H T, Spicker S F, White $\mathrm{J} \mathrm{M}$, eds. New knowledge in the biomedical sciences. Dordrecht: D Reidel, 1982: 23-31.

(8) Jonas H. Philosophical reflections on experimenting with human subjects. In: Freund P A. ed. Experimentation with human subjects. New York: George Brazilles, 1969: 1-31.

(9) Smith A. The ethics of society rather than medical ethics. Fournal of medical ethics 1982; 8: 120-121.

(10) Arras J D, Murray T H. In defence of clinical bioethics. Foumal of medical ethics $1982 ; 8$ : 122-127.

(11) Thomasma D C. A philosophy of clinically based medical ethics. Fournal of medical ethics 1980; 6: 190-196.

(12) Jonas H. Is God a mathematician? Measure 1951; 2: 404-426.

(13) Toulmin S. How medicine saved the life of ethics. Perspectives in biology and medicine 1982; 25: 736-750.

\section{Contributors to this issue}

W E Waters is Professor of Community Medicine at Southampton University.

Pauline Allen is Research Assistant in the Department of Community Medicine, Southampton University.

L W Osborne is the Deputy Medical Superintendent at Austin Hospital in Melbourne.

The Hon Mr Justice M D Kirby is Chairman of the Law Reform Commission of Australia.

Arthur Schafer is Associate Professor in the Department of Philosophy, University of Manitoba and Professor of Bio-medical Ethics in the Faculty of Medicine at the same university.

G Kienle is head of the Institut für klinische Pharmakologie, Herdecke, Federal Republic of Germany and $\mathbf{R}$ Burkhardt is head of the statistical department of the institute. Both have been engaged in problems concerning controlled trials for about ten years and in Germany are regarded as specialists and among the most influential critics in this field.

Duncan Vere is Professor of Therapeutics in the University of London, Consultant Physician at the London Hospital, and Chairman of the Tower Hamlets District Ethics Committee.
Arnold Byer is Chief of Vascular Surgery at the Hackensack Medical Center, Hackensack, New Jersey, and Clinical Associate Professor at the New Jersey Medical College, Newark, New Jersey.

Michael Baum is Professor of Surgery at King's College Hospital Medical School and Honorary Director, Cancer Research Campaign Cancer Trial Centre.

R G Frey is Senior Lecturer in Philosophy in the University of Liverpool.

Sir William Paton is Professor of Pharmacology in the University of Oxford and is currently on the Home Office Advisory Committee on Animal Experimentation.

T L S Sprigge is Professor of Logic and Metaphysics at the University of Edinburgh.

Michael Kottow is Deputy Chief Ophthalmologist, Charlottenklinik für Augenkranke, Stuttgart, Federal Republic of Germany.

Sir Immanuel Jakobovits is Chief Rabbi of the British Commonwealth and specialises - as writer, lecturer and adviser - in Jewish medical ethics. His book, fewish Medical Ethics, was the first ever written in this field.

Case conference editor

Roger Higgs, 81 Brixton Water Lane, London SW2 IPH.

American correspondent

Bernard Towers, Department of Pediatrics, University of California at Los Angeles. 